\title{
Review Article \\ Role of Oxidative Stress in the Pathophysiology of Pneumococcal Meningitis
}

\author{
Tatiana Barichello, ${ }^{1,2,3}$ Jaqueline S. Generoso, ${ }^{1,2,3}$ Lutiana R. Simões, ${ }^{1,2,3}$ \\ Samuel G. Elias, ${ }^{1}$ and João Quevedo ${ }^{2,3,4}$ \\ ${ }^{1}$ Laboratório de Microbiologia Experimental, Programa de Pós-Graduação em Ciências da Saúde, \\ Unidade Acadêmica de Ciências da Saúde, Universidade do Extremo Sul Catarinense, 888806-000 Criciúma, SC, Brazil \\ ${ }^{2}$ Instituto Nacional de Ciência e Tecnologia Translacional em Medicina (INCT-TM), \\ Programa de Pós-Graduação em Ciências da Saúde, Unidade Acadêmica de Ciências da Saúde, \\ Universidade do Extremo Sul Catarinense, 88806-000 Criciúma, SC, Brazil \\ ${ }^{3}$ Núcleo de Excelência em Neurociências Aplicadas de Santa Catarina (NENASC), Programa de Pós-Graduação em Ciências da Saúde, \\ Unidade Acadêmica de Ciências da Saúde, Universidade do Extremo Sul Catarinense, 88806-000 Criciúma, SC, Brazil \\ ${ }^{4}$ Laboratório de Neurociências, Programa de Pós-Graduação em Ciências da Saúde, Unidade Acadêmica de Ciências da Saúde, \\ Universidade do Extremo Sul Catarinense, 888806-000 Criciúma, SC, Brazil
}

Correspondence should be addressed to Tatiana Barichello; tba@unesc.net

Received 6 March 2013; Accepted 18 April 2013

Academic Editor: Francisco Javier Romero

Copyright (C) 2013 Tatiana Barichello et al. This is an open access article distributed under the Creative Commons Attribution License, which permits unrestricted use, distribution, and reproduction in any medium, provided the original work is properly cited.

\begin{abstract}
Pneumococcal meningitis is a life-threatening disease characterized by an acute purulent infection affecting the pia mater, the arachnoid, and the subarachnoid spaces. Streptococcus pneumoniae crosses the blood-brain barrier (BBB) by both transcellular traversal and disruption of the intraepithelial tight junctions to allow intercellular traversal. During multiplication, pneumococci release their bacterial products, which are highly immunogenic and may lead to an increased inflammatory response in the host. Thus, these compounds are recognized by antigen-presenting cells through the binding of toll-like receptors. These receptors induce the activation of myeloid differentiation factor 88 (MyD88), which interacts with various protein kinases, including IL-1 receptor-associated kinase-4 (IRAK4), which is phosphorylated and dissociated from MyD88. These products also interact with tumor necrosis factor receptor-associated factor 6 dependent signaling pathway (TRAF6). This cascade provides a link to NF$\kappa \mathrm{B}$-inducing kinase, resulting in the nuclear translocation of NF- $\kappa \mathrm{B}$ leading to the production of cytokines, chemokines, and other proinflammatory molecules in response to bacterial stimuli. Consequently, polymorphonuclear cells are attracted from the bloodstream and then activated, releasing large amounts of $\mathrm{NO}^{\circ}, \mathrm{O}_{2}{ }^{\circ}$, and $\mathrm{H}_{2} \mathrm{O}_{2}$. This formation generates oxidative and nitrosative stress, subsequently, lipid peroxidation, mitochondrial damage, and BBB breakdown, which contributes to cell injury during pneumococcal meningitis.
\end{abstract}

\section{Introduction}

Pneumococcal meningitis is the most complex and serious infection of the central nervous system (CNS) that is associated with neurological sequelae [1]. The host immune response, through the production of cytokines and chemokines and the migration of leukocytes, is the first line of defense in response to bacterial infection [2]. In addition, polymorphonuclear leukocytes produce nitric oxide $\left(\mathrm{NO}^{\circ}\right)$, superoxide anion radicals $\left(\mathrm{O}_{2}{ }^{-\bullet}\right)$, and hydrogen peroxide
$\left(\mathrm{H}_{2} \mathrm{O}_{2}\right) \cdot \mathrm{O}_{2}^{-\bullet}$ and $\mathrm{NO}^{\bullet}$ can lead to the formation of peroxynitrite (ONOO), which is a strong oxidant [3]. This oxidant exerts cytotoxic effects on endothelial cells [4], increases the permeability of the BBB, induces the peroxidation of lipids, and induces many other complex interactions that seem to be involved in the pathophysiology of pneumococcal meningitis [3].

The aim of this review is to summarize the current knowledge of the relevant pathophysiological steps of pneumococcal meningitis: (a) the crossing of the pneumococcus 


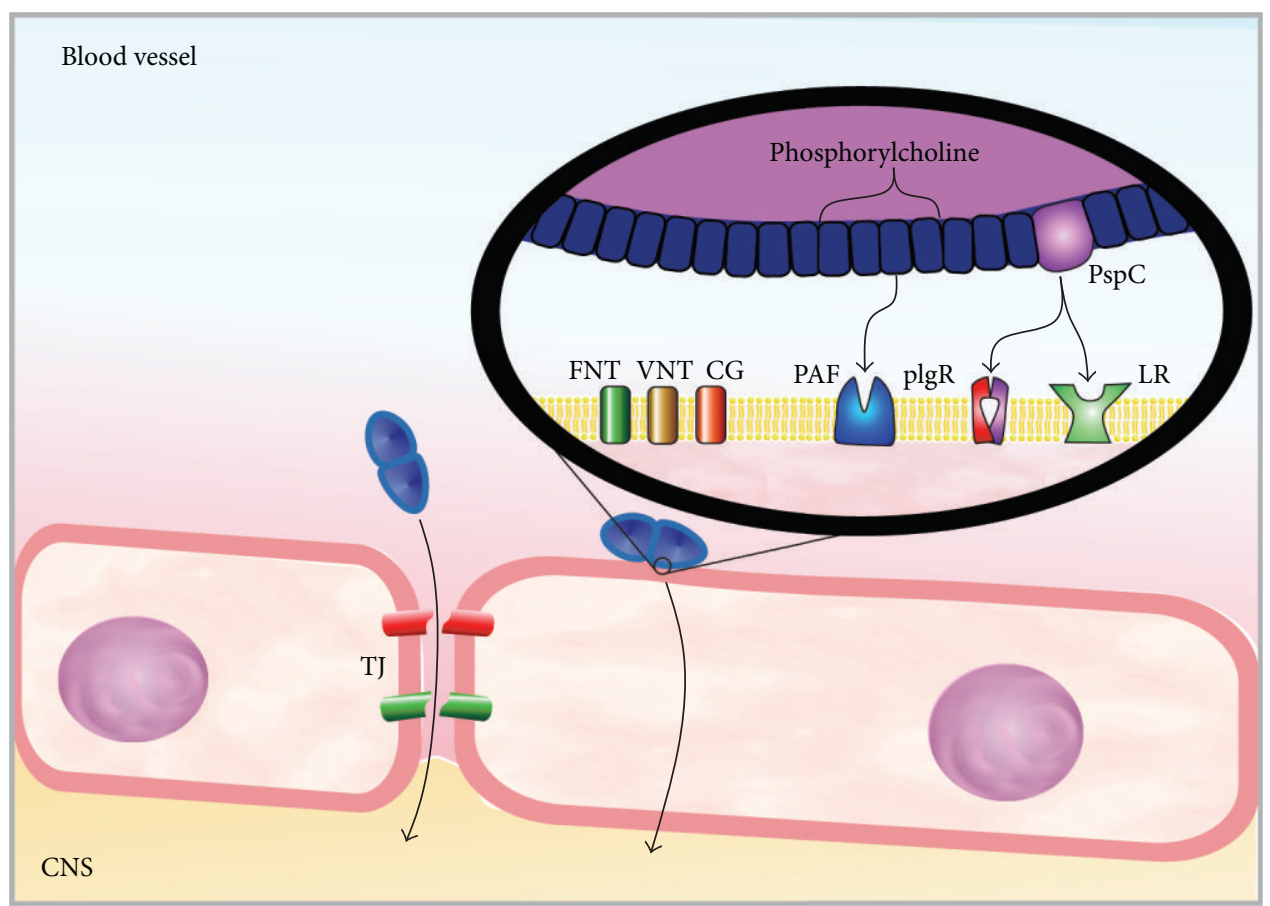

FIGURE 1: Mechanisms of microbial traversal of the BBB. S. pneumoniae crosses the BBB through transcellular traversal and paracellular traversal.

through the $\mathrm{BBB}$; (b) the activation of innate immune system mechanisms; (c) the migration of leukocytes and (d) the induction of oxidative and nitrosative stress in the context of pneumococcal meningitis.

\section{Microbial Traversal of the Blood-Brain Barrier}

The CNS is protected by a bony skull, the leptomeninges, the blood-brain barrier (BBB), and the blood-cerebrospinal fluid barrier [5]. The $\mathrm{BBB}$ is formed by microvascular endothelial cells, astrocytes, and pericytes. This barrier acts by controlling the exchange of substances into and out of the brain [6] and thereby protects the brain from toxins and pathogens [5]. S. pneumoniae crosses the BBB through both transcellular traversal and paracellular traversal $[6,7]$. In transcellular traversal, the pathogen interacts with cell-wall phosphorylcholine and the platelet-activating-factor (PAF) receptor. In addition, the protein $\mathrm{C}(\mathrm{PspC})$ pneumococcal surface binds to both the laminin receptor and the polymeric Ig receptor (pIgR), which are located on brain microvascular endothelial cells [8]. Later, the pathogen transmigrates through endothelial cells to the basolateral side without any evidence of disruption of intercellular tight junctions $[5,6]$.

Paracellular traversal involves the penetration of bacteria between barrier cells with or without evidence of tightjunction disruption [6]. Both the host immune response and bacterial virulence factors, such as pneumolysin, and the ability of pneumococci to bind to fibronectin [9], vitronectin, and collagen in the extracellular matrix, act together to increase the permeability of the $\mathrm{BBB}[10,11]$. This interaction facilitates the passage of the microorganism into the brain [1] Figure 1.

\section{Innate Immune Mechanisms of the Pneumococcal Meningitis}

After S. pneumoniae reaches the subarachnoid space, it multiplies rapidly and releases compounds, such as cell wall fragments, lipoteichoic acid, teichoic acid, pneumolysin, and peptidoglycan [1]. These compounds are highly immunogenic and may elicit an inflammatory response in the host. These immunogenic molecular determinants are better known as pathogen-associated molecular patterns (PAMPs) [12, 13]. These PAMPs are recognized by different sensors of the innate immune system called pattern recognition receptors (PRRs) [14]. These PRRs comprise toll-like receptors (TLRs), NODlike receptors (NLRs), and DNA sensors $[14,15]$. At present, there are 13 members of the TLR family described in humans and 10 described in mice. These members are separated into two broad categories. One category is expressed at the cell surface for extracellular ligand recognition. The other category is localized in the endosomal compartment for the recognition of pathogen nucleic acids [16]. Microglia express all TLRs identified to date, whereas astrocytes only express TLR1, TLR2, TLR3 and TLR9. Neurons only express TLR3, TLR7, TLR8, and TLR9, and oligodendrocytes only express TLR2 and TLR3 [15, 17]. TLR2 is activated by pneumococcal cell wall compounds, lipoteichoic acid, and lipoproteins. TLR4 is activated by pneumolysin, and TLR9 is activated by pneumococcal DNA containing CpG motifs within endosomes $[14,15]$. TLR2, TLR4, and TLR9 transduce 
their signals through a common intracellular adapter protein known as myeloid differentiation factor 88 (MyD88) [14, 18]. Of note, the deficiency of this intracellular adapter protein in children increases their susceptibility to invasive pneumococcal infections, including meningitis [19]. MyD88 interacts with a protein kinase, IL-1 receptor-associated kinase4 (IRAK4) $[1,20]$. The IRAK4 dependent, TLRs, and IL1Rs are vital for childhood immunity to pyrogenic bacteria, which are mainly invasive pneumococcal infections [21]. After IRAK has been phosphorylated, it is dissociated from MyD88 and interacts with tumor necrosis factor receptorassociated factor 6 dependent signaling pathway (TRAF6) [22]. TRAF6 stimulates the transforming growth factor $\beta$ activated kinase (TAK1), which is a MAPKKK. Thus, TAK1 activates IKK (Inhibitor of IkB kinase), which results in the destruction of IkB and the subsequent activation and nuclear translocation of NF- $\kappa \mathrm{B}[23,24]$. NF- $\kappa \mathrm{B}$ comprises a closely related family of transcription factors, which play a key role in the expression of genes involved in the development of accessory cell and leukocyte populations, inducing the expression of many proteins implicated in inflammation and in the immune response [25]. NF- $\kappa \mathrm{B}$ is also a transcriptional activator of various genes implicated in neuronal pathogenesis and in the production of cytokines and chemokines $[20,26]$. The nucleotide-binding-oligomerization-domainsNOD-like receptors (NLRs) are also involved in the recognition of $S$. pneumoniae by the innate immune system. The family members consist of intracellular receptors, such as inflammasome-forming proteins (NLRPs), NLRP1, NLRP3, and NLRP6, which mediate the assembly of inflammasome complexes leading to the activation of procaspase- 1 . The second group of NLRs includes intracellular recognition receptors, such as NOD1/CARD4 and NOD2/CARD15. These receptors mediate the assembly of complexes that activate MAPK and NF- $\kappa$ B signaling pathways, and they are involved in the detection of cell wall peptidoglycan $[27,28]$. NLRP3 (cryopyrin) and AIM2 (absent in melanoma 2) inflammasomes are activated by pneumolysin and bacterial DNA. These inflammasomes use an adapter molecule, known as apoptosis-associated speck-like protein (ASC), which is a key component of multimeric protein complexes that mediate inflammation and host defenses [29]. NLRP3 and AIM2 promote caspase-1 activation and the subsequent conversion of pro-IL- $1 \beta$ into mature IL- $1 \beta$ in pneumococcal meningitis [30]. Furthermore, pneumolysin activates the NLRP3 inflammasome and promotes the production of the proinflammatory cytokines independently of TLR4 [31], Figure 2.

\section{Leukocyte Migration}

Pneumococcal compounds are proinflammatory mediators that induce an innate immune response that activates NF$\kappa \mathrm{B}$ and subsequently triggers the production of proinflammatory cytokines and chemokines and the expression of costimulatory molecules [32]. In response, neutrophils leave the blood and migrate to sites of infection. Sialyl-Lewis ${ }^{\mathrm{X}}$ on leukocytes binds to selectins $\mathrm{P}$ and $\mathrm{E}$ on endothelial cells. This binding becomes stronger when CXCL- 8 binds to its specific

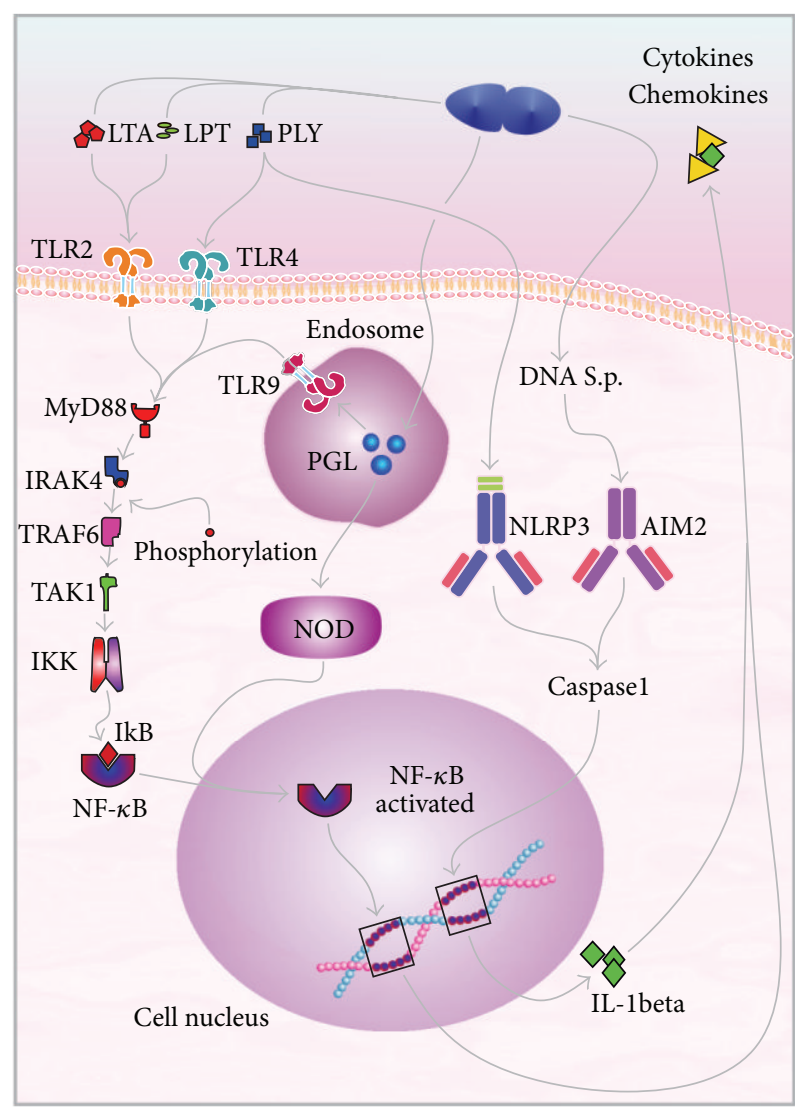

FIGURE 2: Innate immune system in pneumococcal meningitis infection. The majority of TLRs utilize a common intracellular adapter protein known as myeloid differentiation factor 88 (MyD88): it activates IRAK, which is phosphorylated and dissociated from MyD88. Thus, it interacts with the tumor necrosis factor receptorassociated factor 6 dependent signaling pathway (TRAF6). TRAF6 stimulates to the transforming growth factor $\beta$-activated kinase (TAK1). TAK1 activates the IKK (Inhibitor of I $\kappa$ B kinase), resulting in the destruction of IkB and subsequently, NF- $\kappa \mathrm{B}$ activation resulting in the nuclear translocation of NF- $\kappa$ B. This cascade provides a link to NF- $\kappa \mathrm{B}$-inducing kinase, resulting in the nuclear translocation of NF- $\kappa \mathrm{B}$, which induces the production of cytokines, chemokines, and others proinflammatory molecules in response to bacterial stimuli.

receptor on neutrophils, which triggers the production of integrin LFA-1 and CX3 (mac-1). Inflammatory cytokines, such as TNF- $\alpha$, are also necessary to induce expression of adhesion molecules ICAM-1 and ICAM-2. The link between endothelial cells and ICAM-1 allows the passage of neutrophils along a gradient of chemoattractants substances [33, $34]$, Figure 3. Consistent with the polymorphonuclear migration, as explained previously, TNF- $\alpha$ is produced mainly in the first 6 to 24 hours after pneumococcal meningitis induction [35]. Patients with bacterial meningitis also have increased the levels of TNF- $\alpha$ in the CSF early in the course of the disease [36]. In bacterial meningitis, approximately $90 \%$ of the migrating leukocytes are neutrophilic granulocytes [37]. However, blocking the accumulation of leukocytes in 


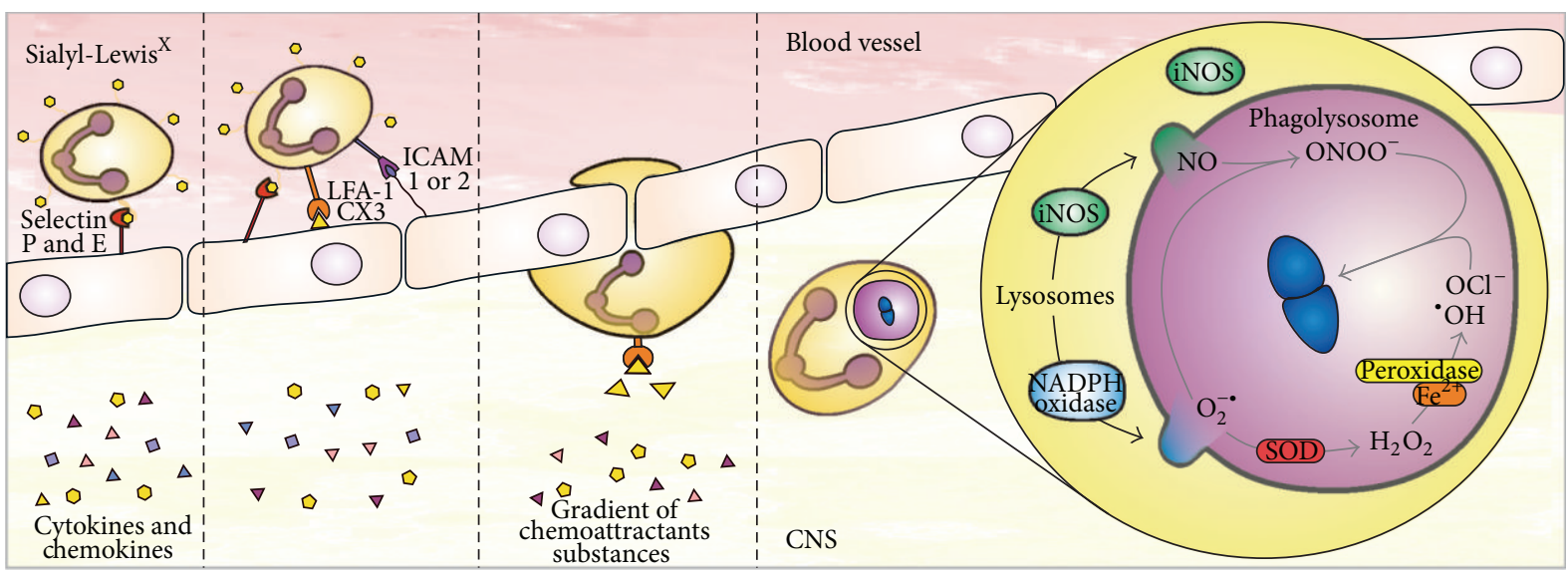

FIGURE 3: Leukocyte migration. Leukocytes leave the blood and migrate to sites of infection. Sialyl-Lewis ${ }^{\mathrm{X}}$ on leukocytes binds to selectins $\mathrm{P}$ and $\mathrm{E}$ on endothelial cells. This binding becomes stronger when CXCL-8 binds to its specific receptor on neutrophils, triggering the production of integrin LFA-1 and CX3 (mac-1). Inflammatory cytokines, such as TNF- $\alpha$, are also necessary to induce expression of the adhesion molecules ICAM-1 and ICAM-2. The interaction between endothelial cells and ICAM-1 allows the passage of neutrophils along a gradient of chemoattractants substances.

cerebrospinal fluid augments bacteremia and lethality in experimental pneumococcal meningitis [38].

Initially, phagocytized pathogens are internalized in the phagosome. The phagosome is acidified by fusion with lysosomes, becoming a phagolysosome. In this period, high amounts of reactive oxygen species (ROS) and reactive nitrogen species (RNS) are formed [39]. The relevant antimicrobial systems of phagocytic cells are the NADPH phagocytic oxidase and inducible nitric oxide synthase (iNOS) pathways, which are expressed in neutrophil and macrophage cells [40]. Macrophages and neutrophils produce $\mathrm{NO}^{*}, \mathrm{O}_{2}{ }^{-\boldsymbol{*}}$, and $\mathrm{H}_{2} \mathrm{O}_{2}$. $\mathrm{NO}^{\bullet}$ is produced by $\mathrm{iNOS}_{2}$, and $\mathrm{O}_{2}{ }^{-\bullet}$ is produced by NADPH oxidase. $\mathrm{O}_{2}{ }^{-\bullet}$ and $\mathrm{NO}^{\bullet}$ can lead to the formation of $\mathrm{ONOO}^{-}$ [3], which is a strong oxidant that exerts cytotoxic effects on endothelial and vascular smooth muscle cells [4]. Moreover, chemical and enzymatic reactions produce a variety of toxic chemical agents; $\mathrm{O}_{2}{ }^{-\bullet}$ is converted by the enzyme superoxide dismutase (SOD) into $\mathrm{H}_{2} \mathrm{O}_{2}[38,39] . \mathrm{H}_{2} \mathrm{O}_{2}$ can kill the microorganisms and also be converted by the peroxidase enzyme in the presence of $\mathrm{Fe}^{2+}$ into hypochlorite $\left(\mathrm{OCl}^{-}\right)$and hydroxyl radicals $\left({ }^{\circ} \mathrm{OH}\right)$, which are microbicides $[3,39,41]$.

\section{Oxidative Stress in the Context of Pneumococcal Meningitis}

During pneumococcal meningitis, RNS and ROS are produced by resident immune cells of the brain as part of the host response to invasive bacterial infections $[1,42]$. Furthermore, ROS are produced in greater quantities in neutrophils than in macrophages; however, macrophages produce more RNS than neutrophils [43]. S. pneumoniae also produces $\mathrm{H}_{2} \mathrm{O}_{2}$, which interacts with $\mathrm{NO}^{-}$forming $\mathrm{ONOO}^{-}[44,45]$. $\mathrm{ONOO}^{-}$ can damage neurons and glial cells by lipid peroxidation and cell membrane destabilization; it can also cause DNA disintegration and subsequent poly (ADP-ribose) polymerase (PARP) activation, which leads to cell energy reduction and cell death [2]. In pneumococcal meningitis, adjuvant therapy with an $\mathrm{ONOO}^{-}$scavenger reduces the number of CSF leukocytes concentrations and reduces the brain concentrations of IL-1 $\beta$ and MIP-2 [46]. This reduction is associated with a decrease of the number of leukocytes in the CSF, suggesting the involvement of ROS/RNS and proinflammatory cytokines and chemokines in the attraction of leukocytes from the blood into the subarachnoid space [3]. $\mathrm{ONOO}^{-}$can contribute to the development of meningeal inflammation and increase the production of IL-8. This chemokine is equivalent to rat MIP-2; it is a chemoattractant and is involved in the migrations of leukocytes in pneumococcal meningitis [47]. In addition, treatment with a monoclonal antibody that binds with IL-8 attenuates pleocytosis in experimental pneumococcal meningitis in rabbits [48].

In vitro, the production of cytokines by human mononuclear cells was regulated by $\mathrm{ONOO}^{-}$. This activation was mediated via the transcription factor NF- $\kappa$ B by a mechanism that may involve nitration or dephosphorylation of $\mathrm{I} \kappa \mathrm{B}-\mathrm{a}$ which leads to NF- $\kappa \mathrm{B}$ translocation and release of TNF- $\alpha$ [49].

One of the major and first pathologies during pneumococcal meningitis is the breakdown of the BBB. In an animal model, the BBB breakdown occurred at 12 hours after pneumococcal meningitis induction [50], subsequent to the cytokine production [35]. ROS and RNS have been implicated as mediators of the $\mathrm{BBB}$ breakdown [3], suggesting that the increase of the $\mathrm{BBB}$ permeability appears to be related to the presence of $\mathrm{NO}^{-}$and $\mathrm{O}_{2}{ }^{-\bullet}$ [51]. Furthermore, treatment with antioxidant prevented BBB disruption $[41,46]$.

Neurological sequelae from pneumococcal meningitis are estimated to occur in 30 to $52 \%$ of surviving patients $[1,52]$. This damage has been demonstrated in a bacterial meningitis animal model; in this model, the surviving animals showed memory and learning impairment, depressivelike-behaviors, and anxiety-like symptoms [53]. In addition, coadjuvant treatment with antioxidants prevented cognitive 
impairment and oxidative stress in the brain of the survivor rats of the bacterial meningitis animal model [54]. ROS and RNS are related to these cognitive sequelae because of the cellular damage that they cause. The nervous system is a unique network of diverse cell types, comprising multiple proteins, lipids, and carbohydrates, and has important interactions with all major organs in the body [55]. Thus, the brain becomes particularly vulnerable to oxidative damage due to its high oxygen consumption, the abundance of iron, relatively low expression of antioxidants levels [55], and high presence of the polyunsaturated fatty acids [3]. $\mathrm{H}_{2} \mathrm{O}_{2}$ and pneumolysin produced by pneumococcus can cause neuronal cell death through mitochondrial damage $[45,56]$, leading to the release of apoptosis-inducing factor (AIF) into the cytosol and subsequently inducing apoptosis by a caspase-independent pathway [56]. Furthermore, leukocytes activate the tumor suppressor protein (p53) and the ataxia telangiectasia-mutated (ATM) kinase, which induce mitochondria to release cytochrome-c. Cytochrome-c, Apaf-1, and dATP/ATP are needed to form the apoptosome which is a special protein complex. Subsequently, apoptosome activates the caspase-9, that results in the activation of caspase- 3 and apoptosis [56, 57]. The formation of ROS can cause direct damage through lipid peroxidation and carbonylation. Lipid peroxidation can be increased in serum [58] and in the CSF of children with bacterial meningitis [59].

\section{Conclusion}

Understanding the interactions between the complex immune network, composed of cytokines, chemokine, leukocytes, and oxidative stress, and bacterial virulence factors may help to establish more effective therapeutic strategies for CNS infections and, therefore, a better outcome for affected subjects.

\section{Abbreviations}

AIF: Apoptosis-inducing factor

AIM2: Absent in melanoma 2

Apaf: Apoptosis protease activating

factor

ASC: apoptosis speck-like protein

ATM: Ataxia telangiectasiamutated

BBB: Blood-brain barrier

CNS: Central nervous system

CSF: Cerebrospinal fluid

CXCL-8: Interleukin 8

DNA: Desoxyribonucleic acid

$\mathrm{Fe}^{2}$ : $\quad$ Iron ion

$\mathrm{H}_{2} \mathrm{O}_{2}$ : Hydrogen peroxide

ICAM: Intercellular adhesion molecule

IkB: Immunome knowledge base

IKK: Immunome knowledge base kinase

IL: $\quad$ Interleukin

IL-1Rs: interleukin receptors

iNOS: Inducible nitric oxide synthase
IRAK4: IL-1 receptor-associated kinase-4

LFA: Lymphocyte-function-associated antigen

MAPKKK: Mitogen-activated protein kinase kinase kinase

MIP-2: $\quad$ Macrophage inflammatory protein

MyD88: $\quad$ Myeloid differentiation factor 88

NADPH: Nicotinamide adenine dinucleotide phosphate

NF- $\kappa$ B: $\quad$ Nuclear factor kappa B

NLR: NOD-Like receptor

NO: $\quad$ Nitric oxide

NOD/CARD: Nucleotide oligomerization domain/caspase recruitment domain

$\mathrm{O}_{2}^{-\bullet}: \quad$ Superoxide anion radicals

OCl: Hypochlorite

$\mathrm{OH}: \quad$ Hydroxyl radicals

ONOO-: $\quad$ Peroxynitrite

PAF: Platelet-activating-factor

PAMP: $\quad$ Pathogen-associated molecular patterns

PARP: $\quad$ Poly-ADP-ribose polymerase

pIgR: $\quad$ Polymeric Ig receptor

PRRs: $\quad$ Pattern recognition receptors

PspC: $\quad$ Protein C pneumococcal surface

RNS: $\quad$ Reactive nitrogen species

ROS: Reactive oxygen species

S. pneumoniae: Streptococcus pneumoniae

SOD: $\quad$ Superoxide dismutase

TAK1: $\quad$ TGF- $\beta$-activated kinase 1

TLR: Toll-like receptor

TRAF6: Tumor necrosis factor receptor associated factor 6 .

\section{Conflict of Interests}

The authors declare that they have no conflict of interests.

\section{Acknowledgments}

This research was supported by grants from $\mathrm{CNPq}$, FAPESC, UNESC, NENASC project (PRONEX program CNPq/FAPESC), INCT-TM, and L'Oréal-UNESCO Brazil Fellowship for Women in Science 2011.

\section{References}

[1] B. B. Mook-Kanamori, M. Geldhoff, T. van der Poll, and D. van de Beek, "Pathogenesis and pathophysiology of pneumococcal meningitis," Clinical Microbiology Reviews, vol. 24, no. 3, pp. 557-591, 2011.

[2] W. M. Scheld, U. Koedel, B. Nathan, and H. W. Pfister, "Pathophysiology of bacterial meningitis: mechanism(s) of neuronal injury," Journal of Infectious Diseases, vol. 186, supplement 2, pp. S225-S233, 2002.

[3] M. Klein, U. Koedel, and H. W. Pfister, "Oxidative stress in pneumococcal meningitis: a future target for adjunctive therapy?" Progress in Neurobiology, vol. 80, no. 6, pp. 269-280, 2006.

[4] C. Szabó, "Multiple pathways of peroxynitrite cytotoxicity," Toxicology Letters, vol. 140-141, pp. 105-112, 2003. 
[5] K. S. Kim, "Mechanisms of microbial traversal of the bloodbrain barrier," Nature Reviews Microbiology, vol. 6, no. 8, pp. 625-634, 2008.

[6] K. S. Kim, "Microbial translocation of the blood-brain barrier," International Journal for Parasitology, vol. 36, no. 5, pp. 607-614, 2006.

[7] T. Barichello, J. S. Generoso, G. Milioli, S. G. Elias, and A. L. Teixeira, "Pathophysiology of bacterial infection of the central nervous system and its putative role in the pathogenesis of behavioral changes," Revista Brasileira de Psiquiatria, vol. 35, no. 1, pp. 81-87, 2013.

[8] J. R. Zhang, K. E. Mostov, M. E. Lamm et al., “The polymeric immunoglobulin receptor translocates pneumococci across nasopharyngeal human epithelial cells," Cell, vol. 102, no. 6, pp. 827-837, 2000.

[9] M. van der Flier, N. Chhun, T. M. Wizemann, J. Min, J. B. McCarthy, and E. I. Tuomanen, "Adherence of Streptococcus pneumoniae to immobilized fibronectin," Infection and Immunity, vol. 63, no. 11, pp. 4317-4322, 1995.

[10] S. Bergmann, A. Lang, M. Rohde et al., "Integrin-linked kinase is required for vitronectin-mediated internalization of Streptococcus pneumoniae by host cells," Journal of Cell Science, vol. 122, no. 2, pp. 256-257, 2009.

[11] M. Kostrzynska and T. Wadström, "Binding of laminin, type IV collagen, and vitronectin by Streptococcus pneumoniae," Zentralblatt fur Bakteriologie, vol. 277, no. 1, pp. 80-83, 1992.

[12] T. Barichello, J. S. Generoso, A. Collodel, A. P. Moreira, and S. M. Almeida, "Pathophysiology of acute meningitis caused by Streptococcus pneumoniae and adjunctive therapy approaches," Arquivos de Neuro-Psiquiatria, vol. 70, no. 5, pp. 366-372, 2012.

[13] J. Sellner, M. G. Täuber, and S. L. Leib, "Pathogenesis and pathophysiology of bacterial CNS infections," in Handbook of Clinical Neurology, L. R. Karen and R. T. Allan, Eds., chapter 1, pp. 1-16, Elsevier, New York, NY, USA, 2010.

[14] U. Koppe, N. Suttorp, and B. Opitz, "Recognition of Streptococcus pneumoniae by the innate immune system," Cellular Microbiology, vol. 14, no. 4, pp. 460-466, 2012.

[15] M. L. Hanke and T. Kielian, "Toll-like receptors in health and disease in the brain: mechanisms and therapeutic potential," Clinical Science, vol. 121, no. 9, pp. 367-387, 2011.

[16] R. Hanamsagar, M. L. Hanke, and T. Kielian, “Toll-like receptor (TLR) and inflammasome actions in the central nervous system," Trends in Immunology, vol. 33, no. 7, pp. 333-342, 2012.

[17] M. L. Hanke, A. Angle, and T. Kielian, "MyD88-dependent signaling influences fibrosis and alternative macrophage activation during Staphylococcus aureus biofilm infection," PLoS ONE, vol. 7, no. 8, Article ID e42476, 2012.

[18] Z. Kronfol and D. G. Remick, "Cytokines and the brain: implications for clinical psychiatry," The American Journal of Psychiatry, vol. 157, no. 5, pp. 683-694, 2000.

[19] H. von Bernuth, C. Picard, Z. Jin et al., "Pyogenic bacterial infections in humans with MyD88 deficiency," Science, vol. 321, no. 5889, pp. 691-696, 2008.

[20] T. Kawai and S. Akira, "Signaling to NF- $\kappa$ B by toll-like receptors," Trends in Molecular Medicine, vol. 13, no. 11, pp. 460-469, 2007.

[21] C. L. Ku, H. von Bernuth, C. Picard et al., "Selective predisposition to bacterial infections in IRAK-4-deficient children: IRAK-4-dependent TLRs are otherwise redundant in protective immunity," Journal of Experimental Medicine, vol. 204, no. 10, pp. 2407-2422, 2007.
[22] A. Adhikari, M. Xu, and Z. J. Chen, "Ubiquitin-mediated activation of TAK1 and IKK," Oncogene, vol. 26, no. 22, pp. 32143226, 2007.

[23] R. Malley, P. Henneke, S. C. Morse et al., "Recognition of pneumolysin by toll-like receptor 4 confers resistance to pneumococcal infection," Proceedings of the National Academy of Sciences of the United States of America, vol. 100, no. 4, pp. 19661971, 2003.

[24] N. S. Kenneth, S. Mudie, S. Naron, and S. Rocha, "TFR1 interacts with the IKK complex and is involved in IKK-NF- $\kappa$ B signalling," Biochemical Journal, vol. 449, no. 1, pp. 275-284, 2013.

[25] C. M. Tato and C. A. Hunter, "Host-pathogen interactions: subversion and utilization of the NF- $\kappa$ B pathway during infection," Infection and Immunity, vol. 70, no. 7, pp. 3311-3317, 2002.

[26] U. Koedel, I. Bayerlein, R. Paul, B. Sporer, and H. W. Pfister, "Pharmacologic interference with NF- $\kappa \mathrm{B}$ activation attenuates central nervous system complications in experimental pneumococcal meningitis," Journal of Infectious Diseases, vol. 182, no. 5, pp. 1437-1445, 2000.

[27] B. Opitz, A. Püschel, B. Schmeck et al., "Nucleotide-binding oligomerization domain proteins are innate immune receptors for internalized Streptococcus pneumoniae," The Journal of Biological Chemistry, vol. 279, no. 35, pp. 36426-36432, 2004.

[28] K. Kersse, M. J. Bertrand, M. Lamkanfi, and P. Vandenabeele, "NOD-like receptors and the innate immune system: coping with danger, damage and death," Cytokine and Growth Factor Reviews, vol. 22, no. 5, pp. 257-276, 2011.

[29] M. Proell, M. Gerlic, P. D. Mace, J. C. Reed, and S. J. Riedl, "The CARD plays a critical role in ASC foci formation and inflammasome signaling," Biochemical Journal, vol. 449, no. 3, pp. 613-621, 2013.

[30] S. Shoma, K. Tsuchiya, I. Kawamura et al., "Critical involvement of pneumolysin in production of interleukin- $1 \alpha$ and caspase-1dependent cytokines in infection with Streptococcus pneumoniae in vitro: a novel function of pneumolysin in caspase-1 activation," Infection and Immunity, vol. 76, no. 4, pp. 1547-1557, 2008.

[31] E. A. McNeela, A. Burke, D. R. Neill et al., "Pneumolysin activates the NLRP3 inflammasome and promotes proinflammatory cytokines independently of TLR4," PLoS Pathogens, vol. 6, no. 11, Article ID e1001191, 2010.

[32] R. A. Hirst, A. Kadioglu, C. O'Callaghan, and P. W. Andrew, "The role of pneumolysin in pneumococcal pneumonia and meningitis," Clinical and Experimental Immunology, vol. 138, no. 2, pp. 195-201, 2004.

[33] T. M. Carlos and J. M. Harlan, "Leukocyte-endothelial adhesion molecules," Blood, vol. 84, no. 7, pp. 2068-2101, 1994.

[34] S. Hanna and A. Etzioni, "Leukocyte adhesion deficiencies," Annals of the New York Academy of Sciences, vol. 1250, pp. 50-55, 2012.

[35] T. Barichello, I. dos Santos, G. D. Savi et al., "TNF- $\alpha$, IL-1 $\beta$, IL-6, and cinc- 1 levels in rat brain after meningitis induced by Streptococcus pneumoniae," Journal of Neuroimmunology, vol. 221, no. 1-2, pp. 42-45, 2010.

[36] F. G. Brivet, F. M. Jacobs, and B. Mégarbane, "Cerebral output of cytokines in patients with pneumococcal meningitis," Critical Care Medicine, vol. 33, no. 11, pp. 2721-2723, 2005.

[37] M. M. J. Polfliet, P. J. G. Zwijnenburg, A. M. van Furth et al., "Meningeal and perivascular macrophages of the central nervous system play a protective role during bacterial meningitis," Journal of Immunology, vol. 167, no. 8, pp. 4644-4650, 2001. 
[38] C. T. Brandt, J. D. Lundgren, N. Frimodt-Møller et al., "Blocking of leukocyte accumulation in the cerebrospinal fluid augments bacteremia and increases lethality in experimental pneumococcal meningitis," Journal of Neuroimmunology, vol. 166, no. 1-2, pp. 126-131, 2005.

[39] S. Kastenbauer, U. Koedel, B. F. Becker, and H. W. Pfister, "Oxidative stress in bacterial meningitis in humans," Neurology, vol. 58, no. 2, pp. 186-191, 2002.

[40] F. C. Fang, "Antimicrobial reactive oxygen and nitrogen species: concepts and controversies," Nature Reviews Microbiology, vol. 2 , no. 10 , pp. 820-832, 2004.

[41] S. Kastenbauer, U. Koedel, and H. W. Pfister, "Role of peroxynitrite as a mediator of pathophysiological alterations in experimental pneumococcal meningitis," Journal of Infectious Diseases, vol. 180, no. 4, pp. 1164-1170, 1999.

[42] A. Aycicek, A. Iscan, O. Erel, M. Akcali, and A. R. Ocak, "Oxidant and antioxidant parameters in the treatment of meningitis," Pediatric Neurology, vol. 37, no. 2, pp. 117-120, 2007.

[43] C. Nathan and M. U. Shiloh, "Reactive oxygen and nitrogen intermediates in the relationship between mammalian hosts and microbial pathogens," Proceedings of the National Academy of Sciences of the United States of America, vol. 97, no. 16, pp. 8841-8848, 2000.

[44] T. J. Mitchell, "Virulence factors and the pathogenesis of disease caused by Streptococcus pneumoniae," Research in Microbiology, vol. 151, no. 6, pp. 413-419, 2000.

[45] J. S. Braun, J. E. Sublett, D. Freyer et al., "Pneumococcal pneumolysin and $\mathrm{H}_{2} \mathrm{O}_{2}$ mediate brain cell apoptosis during meningitis," Journal of Clinical Investigation, vol. 109, no. 1, pp. 19-27, 2002.

[46] S. Kastenbauer, U. Koedel, B. F. Becker, and H. W. Pfister, "Pneumococcal meningitis in the rat: evaluation of peroxynitrite scavengers for adjunctive therapy," European Journal of Pharmacology, vol. 449, no. 1-2, pp. 177-181, 2002.

[47] K. S. Spanaus, D. Nadal, H. W. Pfister et al., "C-X-C and C-C chemokines are expressed in the cerebrospinal fluid in bacterial meningitis and mediate chemotactic activity on peripheral blood-derived polymorphonuclear and mononuclear cells in vitro," Journal of Immunology, vol. 158, no. 4, pp. 1956-1964, 1997.

[48] C. Stergaard, R. V. Yieng-Kow, C. G. Larsen et al., "Treatment with a monoclonal antibody to IL-8 attenuates the pleocytosis in experimental pneumococcal meningitis in rabbits when given intravenously, but not intracisternally," Clinical and Experimental Immunology, vol. 122, no. 2, pp. 207-211, 2000.

[49] B. M. Matata and M. Galiñanes, "Peroxynitrite is an essential component of cytokines production mechanism in human monocytes through modulation of nuclear factor- $\kappa \mathrm{B}$ DNA binding activity," The Journal of Biological Chemistry, vol. 277, no. 3, pp. 2330-2335, 2002.

[50] T. Barichello, J. S. Generoso, C. Silvestre et al., "Circulating concentrations, cerebral output of the CINC-1 and blood-brain barrier disruption in Wistar rats after pneumococcal meningitis induction," European Journal of Clinical Microbiology and Infectious Diseases, vol. 31, no. 8, pp. 2005-2009, 2012.

[51] W. G. Mayhan, "Nitric oxide donor-induced increase in permeability of the blood-brain barrier," Brain Research, vol. 866, no. 1-2, pp. 101-108, 2000.

[52] S. Kastenbauer and H. W. Pfister, "Pneumococcal meningitis in adults: spectrum of complications and prognostic factors in a series of 87 cases," Brain, vol. 126, no. 5, pp. 1015-1025, 2003.
[53] T. Barichello, G. Z. Silva, J. S. Generoso et al., "Time-dependent behavioral recovery after pneumococcal meningitis in rats," Journal of Neural Transmission, vol. 117, no. 7, pp. 819-826, 2010.

[54] T. Barichello, A. L. Santos, G. D. Savi et al., "Antioxidant treatment prevents cognitive impairment and oxidative damage in pneumococcal meningitis survivor rats," Metabolic Brain Disease, vol. 27, no. 4, pp. 587-593, 2012.

[55] R. A. Harris and S. Amor, "Sweet and sour-oxidative and carbonyl stress in neurological disorders," CNS and Neurological Disorders Drug Targets, vol. 10, no. 1, pp. 82-107, 2011.

[56] L. Mitchell, S. H. Smith, J. S. Braun, K. H. Herzog, J. R. Weber, and E. I. Tuomanen, "Dual phases of apoptosis in pneumococcal meningitis," Journal of Infectious Diseases, vol. 190, no. 11, pp. 2039-2046, 2004.

[57] L. Marek, "The role of the apoptosome in the activation of procaspase-9," Postepy Higieny i Medycyny Doswiadczalnej, vol. 67, pp. 54-64, 2013.

[58] H. Çaksen, M. Cemek, S. Dede, H. Dulger, and F. Cemek, "Brief clinical study: lipid peroxidation and antioxidant status in children with acute purulent meningitis and encephalitis," International Journal of Neuroscience, vol. 114, no. 1, pp. 105-111, 2004.

[59] D. Miric, R. Katanic, B. Kisic et al., "Oxidative stress and myeloperoxidase activity during bacterial meningitis: effects of febrile episodes and the BBB permeability," Clinical Biochemistry, vol. 43, no. 3, pp. 246-252, 2010. 


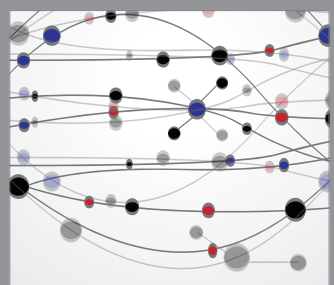

The Scientific World Journal
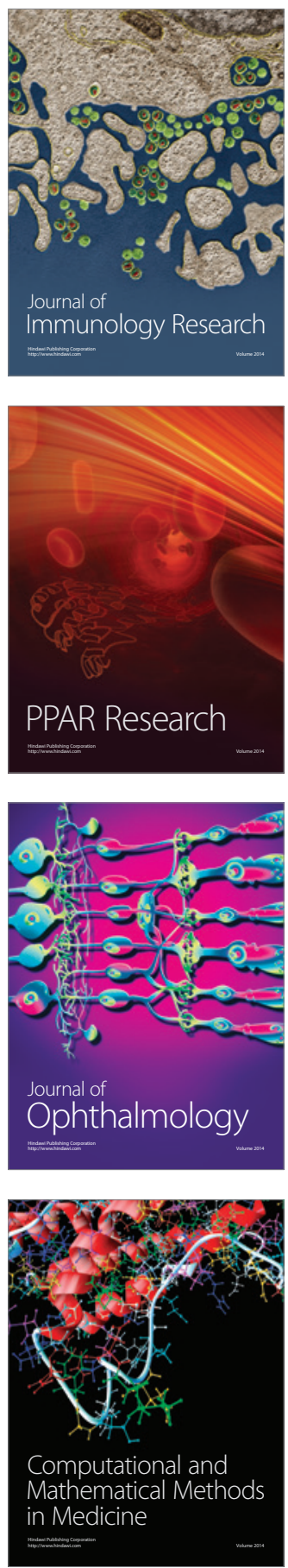

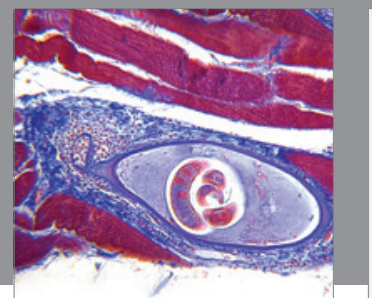

Gastroenterology

Research and Practice
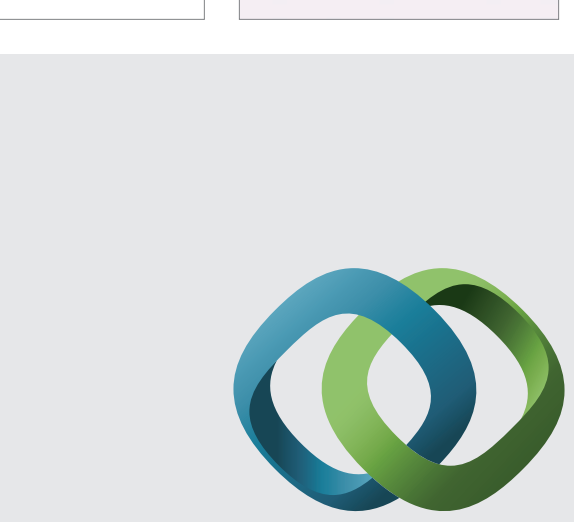

\section{Hindawi}

Submit your manuscripts at

http://www.hindawi.com
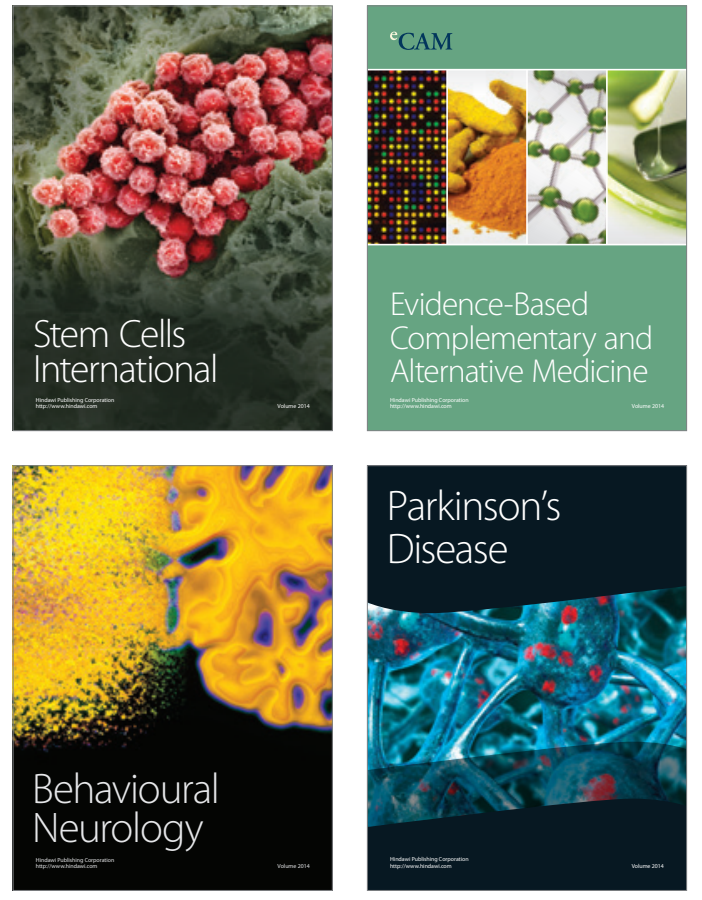
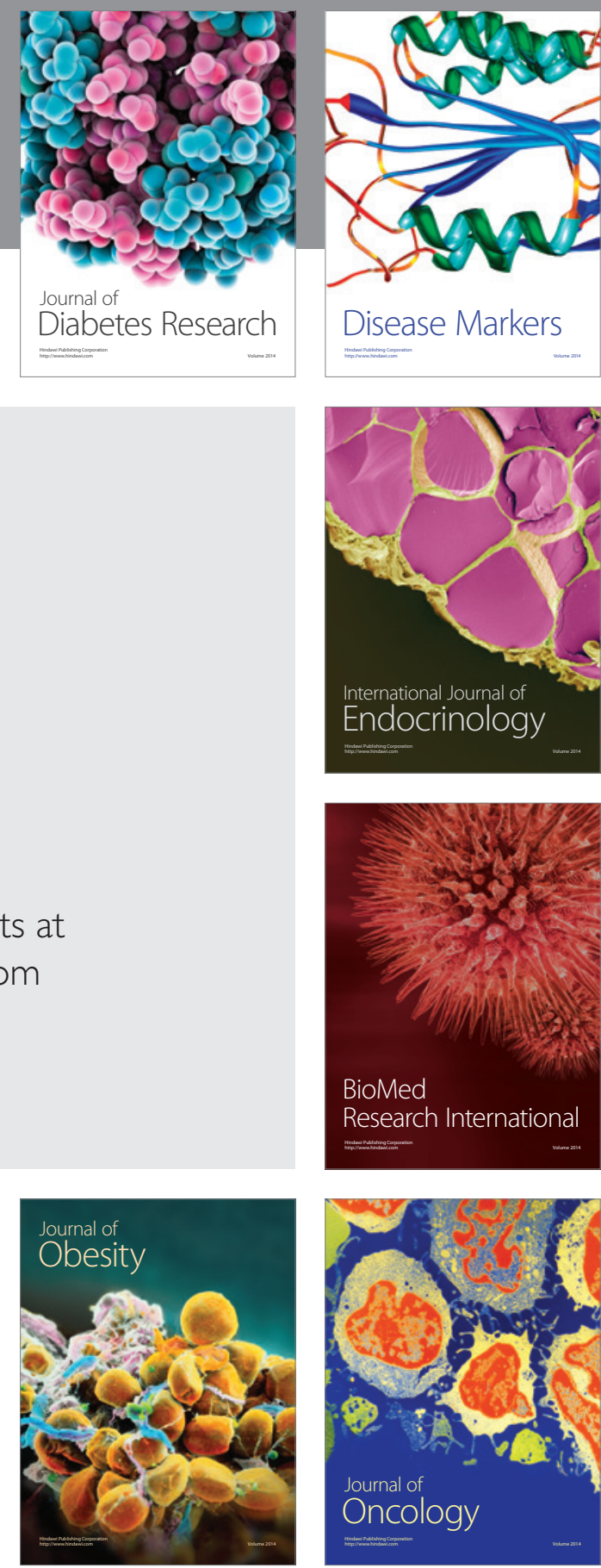

Disease Markers
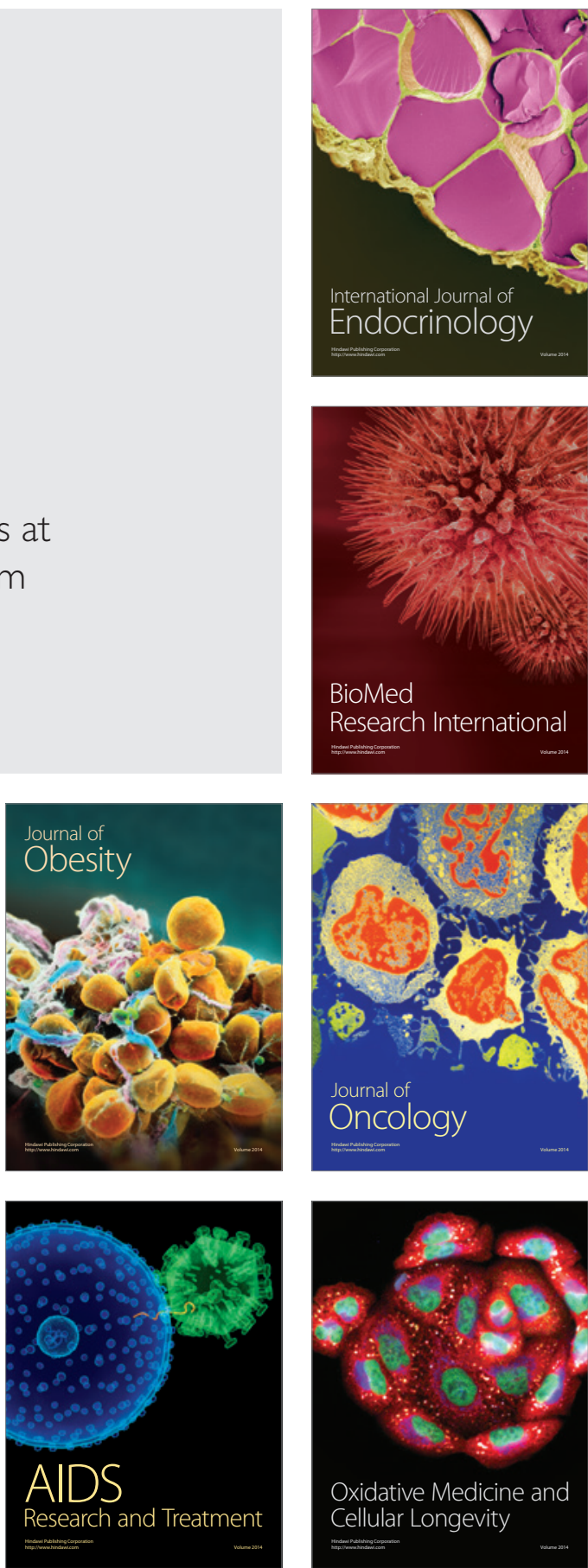